\title{
PREPARATION AND CHARACTERIZATION OF ACTIVATED CARBON FROM WASTE SAWDUST FROM SAW MILL
}

\section{Shrestha, G. Gyawali and A. Rajbhandari (Nyachhyon)}

Journal of Institute of Science and Technology

Volume 22, Issue 2, January 2018

ISSN: 2469-9062 (print), 2467-9240 (e)

\section{Editors:}

Prof. Dr. Kumar Sapkota

Prof. Dr. Armila Rajbhandari

Assoc. Prof. Dr. Gopi Chandra Kaphle Mrs. Reshma Tuladhar

JIST, 22 (2): 103-108 (2018)

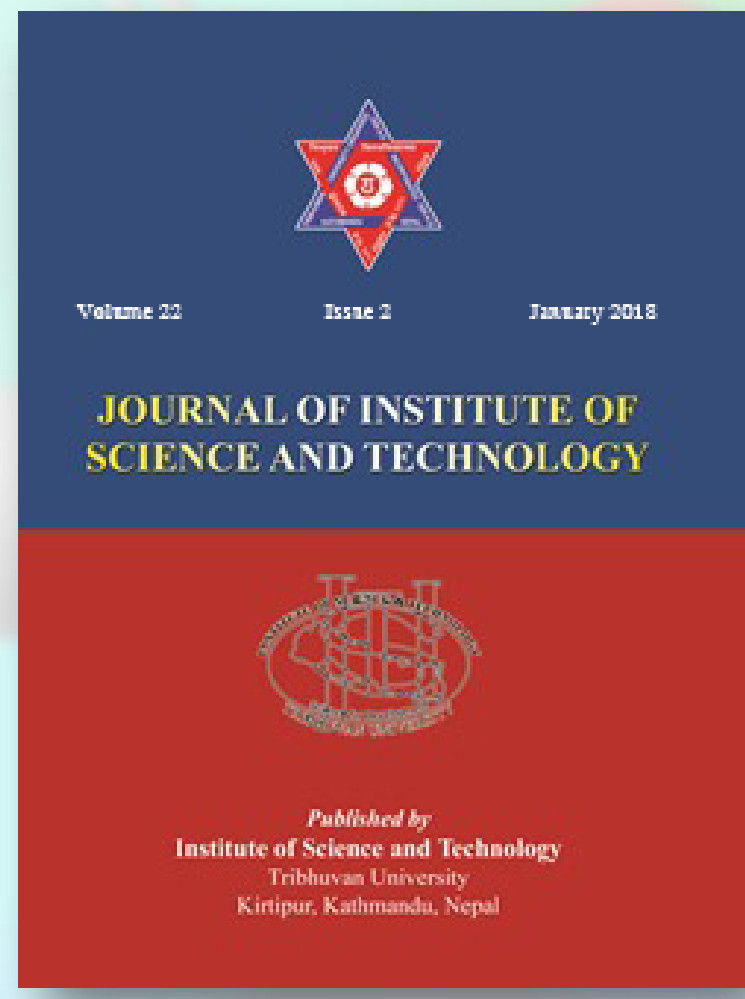

Published by:

Institute of Science and Technology

Tribhuvan University

Kirtipur, Kathmandu, Nepal 


\title{
PREPARATION AND CHARACTERIZATION OF ACTIVATED CARBON FROM WASTE SAWDUST FROM SAW MILL
}

\author{
Dibyashree Shrestha ${ }^{1}$, Gobinda Gyawali ${ }^{2}$, Armila Rajbhandari (Nyachhyon) ${ }^{* 3}$ \\ ${ }^{1}$ Patan Multiple Campus, Tribhuvan University, Lalitpur, Nepal \\ ${ }^{2}$ Research Centre for Eco Multi-Functional Nano Materials, \\ Global Research Laboratory, Sun Moon University, Korea \\ ${ }^{3}$ Central Department of Chemistry, Tribhuvan University, Kathmandu, Nepal \\ *Corresponding E-mail: armila3@yahoo.com
}

Received: 1 November, 2017; Revised: 25 November, 2017; Accepted: 27 November, 2017

\begin{abstract}
Activated carbon was prepared in laboratory using waste sawdust powder of Shorea robusta (Sal) from saw mill by chemically activated $\mathrm{Na}_{2} \mathrm{CO}_{3}$ followed by carbonization technique. Thus prepared activated carbon was characterized by Iodine Number $\left(\mathrm{I}_{\mathrm{N}}\right)$ and Methylene Blue Number $\left(\mathrm{MB}_{\mathrm{N}}\right)$. Iodine number was found to be $534.6 \mathrm{mg} / \mathrm{g}$ whereas $\mathrm{MB}_{\mathrm{N}}$ was found to be $196.08 \mathrm{mg} / \mathrm{g}$ which indicated the presence of micropores as well as mesopores in the prepared material. This was also exposed by SEM image. Specific surface area was measured by BET method and was found to be $10.01 \mathrm{~m}^{2} / \mathrm{g}$. Then phase state of samples was determined by $\mathrm{X}$-ray diffraction (XRD), which indicated the amorphous nature of the prepared material. The development of surface functionality due to activation was examined by Fourier Transform Infrared Spectroscopy (FTIR) which showed the presence of oxygenated functional groups such as ether, diketone, lactone, phenol on the material. These functional groups are considered to be electrochemically active and contribute to the capacitance of electrical double layer capacitance (EDLC). Further, electrochemical characterization of prepared material was carried out by conductivity test and cyclic voltammetry. The cyclic voltametric curve showed symmetric rectangular shape indicating electrical double layer capacitive behavior.
\end{abstract}

Keywords: Wood derived activated carbon, Chemical activation, Conductance, Specific capacitance, EDLC.

\section{INTRODUCTION}

The preparation of activated carbon from woodbased industrial residue like sawdust from sawmill is one of the most environmental friendly solutions of transforming negative-valued wastes to valuable materials. Wood is a natural fiber raw material with varying properties in morphology and chemical composition. The major chemical constituents of wood are cellulose, hemicelluloses and lignin (Chowdhury et al., 2012). Such lingo-cellulosic carbonaceous material can be used for the preparation of activated carbon (Beguin et al., 2010). Activated carbons are unique and versatile in their performance. They have major industrial significance. Activated carbon materials characterized by high specific surface area and tunable porosity find utility in many vital technologies namely energy storage, energy conversion, sensors, environmental protection, production of fine and bulk chemicals, and catalysis
(Nahil et al., 2012). The choice of carbon as the material is due to its unique properties of electrical conductivity as well as structural diversity. Different literatures showed that the activated carbon could be used as electrode materials for electric double layer capacitors (EDLCs), Li-ion batteries and fuel cells (Beguin et al., 2010; Frackowick et al., 2007; Frackowick et al., 2001; Becker et al., 1957, Endo et al., 2001). Preparation of highly porous carbons may be a challenging art and attention has been given for activation (physical and chemical), carbonization and templeting methods using zeolite and mesoporous silica (Pandolfo et al., 2006; Sharma et al., 2010; Wang et al., 2012; Simon et al., 2008; Zhang et al., 2009). Each approach has its own advantages for the formation of carbons with controlled pore texture and /or improved surface area, which are of great importance and considered to be the key factors in optimizing the performance in their 
applications. For energy storage system having high energy density and excellent rate performance is desirable. This study presents preparation of activated carbon from locally available material. Sawdust from Shorea robusta (Sal), a solid residue generated in the timber industry has been selected to prepare activated carbon. The prepared material was subjected for electrochemical characterization.

\section{MATERIALS AND METHODS}

\section{Materials}

All the chemicals and reagents used were of analytical grade and procured from Merck Company. All the experiments were carried out in distilled water. The sawdust of Shorea robusta species has been collected from local saw mill.

\section{Methods}

\section{Preparation of sawdust powder}

The collected waste wood from saw mill was sundried for few days and followed by preliminary stages such as crushing, grinding and sieving through $150 \mu \mathrm{m}$ sized sieve. Thus obtained sawdust powder was used as a precursor for the preparation of activated carbon.

\section{Preparation of activated carbon by} carbonization method

The fine powdered precursor was preheated for two hours and was impregnated with $\mathrm{Na}_{2} \mathrm{CO}_{3}$. The ratio of precursor to activating agent was 1:1 (wt:wt). They were left for 24 hours for proper soaking. After soaking, the precursors were dried in an oven at $110^{\circ} \mathrm{C}$. The dried precursors were carbonized in tube furnace at $400^{\circ} \mathrm{C}$ for 3 hours in an inert atmosphere of nitrogen. Continuous flow of pure nitrogen was used to create an inert atmosphere. The carbonized samples were cooled to room temperature maintaining inert atmosphere of nitrogen. The cooled samples were washed with distilled water for several times till they became neutral. Finally the washed sample was dried in an oven at $110^{\circ} \mathrm{C}$ and stored in air tight bottles. Table 1 show the sample name and preparation condition.

Table1: Sample name and preparation condition

\begin{tabular}{|c|c|c|c|c|c|c|c|}
\hline S.N. & Sample name & $\begin{array}{c}\text { Activating } \\
\text { agent }\end{array}$ & $\begin{array}{c}\text { Preheating } \\
\text { time (hour) }\end{array}$ & $\begin{array}{c}\text { Preheating } \\
\text { temperature } \\
\left({ }^{\circ} \mathbf{C}\right)\end{array}$ & $\begin{array}{c}\text { Carbonization } \\
\text { temperature } \\
\left({ }^{\circ} \mathbf{C}\right)\end{array}$ & $\begin{array}{c}\text { Carbonization } \\
\text { holding time } \\
\text { (hour) }\end{array}$ & Atmosphere \\
\hline 1 & $\mathrm{WAC}^{-} \mathrm{Na}_{2} \mathrm{CO}_{3}$ & $\mathrm{Na}_{2} \mathrm{CO}_{3}$ & 2 & 110 & 400 & 3 & $\mathrm{~N}_{2}$ \\
\hline
\end{tabular}

\section{Sample characterization}

\section{The Proximate analysis}

The proximate analysis of the precursor was conducted according to ASTM D121 (ASTM 2009) and the results are expressed in terms of moisture, volatile matter, fixed carbon, and ash contents.

\section{Determination of Iodine Number $\left(\mathbf{I}_{\mathbf{N}}\right)$}

Iodine number $\left(\mathrm{I}_{\mathrm{N}}\right)$ is a relative indicator of porosity in an activated carbon. It is the measure of micro pores up to $2 \mathrm{~nm}$ size found in activated carbon. It is determined according to the ASTM D4607-94 method (ASTM 1999). $0.1 \mathrm{~g}$ of WAC- $\mathrm{Na}_{2} \mathrm{CO}_{3}$ was separately taken in different conical flasks and added $5 \mathrm{~mL}$ of $5 \% \mathrm{HCl}$, boiled and cooled. To this solution, $10 \mathrm{~mL}$ of $0.1 \mathrm{~N}$ Iodine solution was added. The contents were vigorously shaken for about 4 minutes and filtered. Then $10 \mathrm{~mL}$ filtrate was titrated against standard $(0.1 \mathrm{~N})$ hypo solution using starch as an indicator. The concentration of iodine adsorbed by WAC- $\mathrm{Na}_{2} \mathrm{CO}_{3}$ was calculated by using following equation.

Iodine number $=\mathrm{C} \times$ Conversion factor $(\mathrm{f}) \ldots \ldots$.
Conversion factor is calculated by following equation 2.

Conversion factor $(\mathrm{f})=$ (Molecular weight $\times$ Normality of Iodine $\times 10) /($ Weight of WAC $\times$ Blank reading)

$\mathrm{C}=($ Blank reading - Volume of hypo consumed after adsorption on activated carbon)

Determination of Methylene Blue Number $\left(M B_{N}\right)$

Methylene blue number $\left(M B_{N}\right)$ was considered as a measure of mesoporosity of $2-50 \mathrm{~nm}$ sized pore sand was determined by adsorption of dye per gram of adsorbent. In this study, $0.05 \mathrm{gm}$ of WAC$\mathrm{Na}_{2} \mathrm{CO}_{3}$ was placed in contact with $50 \mathrm{~mL}$ of a methylene blue solutions at different concentration $(50,100,150,200,250$ and $300 \mathrm{mg} / \mathrm{L})$ for 24 hours at room temperature. The suspension was filtered and the remaining concentration of methylene blue was analyzed using UV/vis spectrophotometer. The methylene blue number of WAC- $\mathrm{Na}_{2} \mathrm{CO}_{3}$ (maximum adsorption capacity) was calculated by using Langmuir Isotherm. 
$\mathrm{Q}_{\mathrm{e}}(\mathrm{mg} / \mathrm{g})=\left(\mathrm{C}_{\mathrm{o}}-\mathrm{C}_{\mathrm{e}}\right) \mathrm{V} / \mathrm{M}$

Where,

$\mathrm{Q}_{\mathrm{e}}=$ Amount of methylene blue adsorption

$\mathrm{C}_{\mathrm{o}}(\mathrm{mg} / \mathrm{L})=$ Initial concentration of methylene blue

$\mathrm{C}_{\mathrm{e}}(\mathrm{mg} / \mathrm{L})=$ Equilibrium concentration of methylene blue

$\mathrm{V}(\mathrm{L})=$ Volume of methylene blue

$\mathrm{M}(\mathrm{g})=$ Mass of WAC- $\mathrm{Na}_{2} \mathrm{CO}_{3}$

Scanning Electron Microscopy (SEM): The SEMU-8000, Hitachi Co. Ltd., Japan was used to study surface morphology of theWAC- $\mathrm{Na}_{2} \mathrm{CO}_{3}$.

X-ray Diffraction (XRD): Bruker D-8 Advance Xray Diffractometer using monochromatized $\mathrm{Cu}-\mathrm{K} \alpha$ radiation was used to record XRD.

Fourier Transform Infrared Spectroscopy (FTIR): Surface functional groups present in WAC- $\mathrm{Na}_{2} \mathrm{CO}_{3}$ were estimated by Fourier Transform Infrared (FTIR) Spectroscopy analysis with Thermo Electron Corporation Nicolet 4700 . The $\%$ transmission of samples was recorded over $4000-500 \mathrm{~cm}^{-1}$.

Surface area determination by BET: The specific surface area was measured from nitrogen adsorption- desorption isotherms at $77 \mathrm{~K}$ data using Brunauer, Emmett and Teller (BET).

\section{Electrochemical performance:}

\section{Preparation of electrode}

In order to prepare electrode, $0.3 \mathrm{~g}$ of graphite powder, $0.3 \mathrm{~g}$ of paraffin wax, $0.4 \mathrm{~g}$ of WAC$\mathrm{Na}_{2} \mathrm{CO}_{3}$ was mixed homogenously and heated for few minutes. Then the electrode material was formed which was poured and packed tightly to about $2 \mathrm{~cm}$ at the bottom of $3 \mathrm{~mL}$ plastic syringe. Then the electrical contact was made by keeping a copper wire. This electrode has been used as working electrode.

\section{Preparation of Electrochemical cells}

Three electrode cell system has been applied. Here, as prepared electrode was used as the working electrode, saturated calomel electrode has been used as reference electrode, whereas platinum electrode was used as counter electrode. The electrolyte used here was $0.5 \mathrm{M} \mathrm{H}_{2} \mathrm{SO}_{4}$.

\section{Cyclic Voltammetry (CV)}

Electrochemical performance of WAC- $\mathrm{Na}_{2} \mathrm{CO}_{3}$ was evaluated by Cyclic Voltammetry (CV). The CV measurements were obtained in Potentiostat/Galvanostat by using Polarization Monitor Software interfaced with IBM computer in the potential range of -0.5 to 1 volt. The cyclic stability of prepared ACs was obtained at scan rate of $100 \mathrm{mV} / \mathrm{S}$ for 100 cycles. Capacitance values were estimated from $\mathrm{CV}$.

\section{RESULTS AND DISCUSSION}

\section{Proximate Analysis of Precursor}

The results obtained from proximate analysis of precursor are given in Table 2. It revealed that the moisture and ash content of the precursor was $8.56 \%$ and $1.07 \%$ respectively. This result also showed that the precursor has $31 \%$ of volatile matter, low ash and moisture content. The low ash content in the sample indicates that the precursor contains low inorganic matter.

Table 2: Proximate analysis of sawdust of Shorea robusta (Sal)

\begin{tabular}{|l|l|l|}
\hline S.N. & Parameter & Observed value $(\%)$ \\
\hline 1 & Moisture & 8.56 \\
\hline 2 & Total Ash & 1.07 \\
\hline 3 & Volatile Matter & 31.98 \\
\hline 4 & Total Carbon & 48.0 \\
\hline
\end{tabular}

\section{Iodine Number and Methylene Blue Number}

Iodine number of prepared WAC- $\mathrm{Na}_{2} \mathrm{CO}_{3}$ was found to be 534.6 indicating the presence of micropores in the sample. Similarly, methylene blue number was found to be $196.08 \mathrm{mg} / \mathrm{g}$ indicating presence of mesopores.

\section{Scanning Electron Microscopy (SEM)}

Scanning Electron Microscopic (SEM) image of sample $\mathbf{W A C}-\mathrm{Na}_{2} \mathrm{CO}_{3}$ is presented in figure 1.

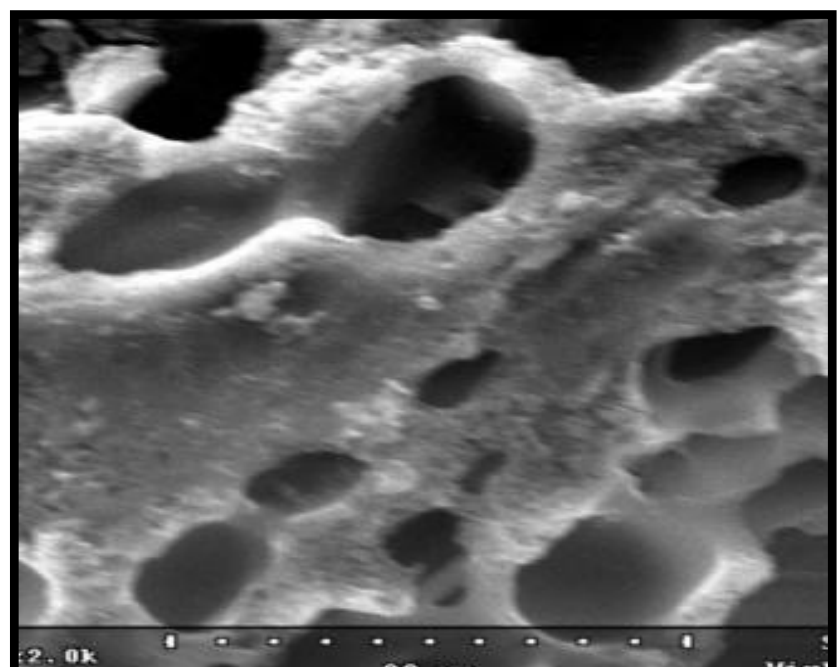

Fig. 1. SEM image of $\mathrm{WAC}-\mathrm{Na}_{2} \mathrm{CO}_{3}$ 
In SEM image of WAC- $\mathrm{Na}_{2} \mathrm{CO}_{3}$, one can observe mesopores along with micropores. Similarly, the cylindrical micro and mesoporous channel could also be seen. Besides this, bigger sized macropores are also obvious on the surface which is anticipated to be responsible for low surface area of this sample. The breakdown of wall of micro and mesopores may have been occurred due to continuous reaction of excess activating agent.

\section{X-ray Diffraction (XRD)}

$\mathrm{X}$-ray diffraction analysis of the sample was carried out in order to determine the degree of crystallinity or amorphous nature of the activated carbons. The $\mathrm{X}$-ray diffraction spectra $\mathrm{WAC}-\mathrm{Na}_{2} \mathrm{CO}_{3}$ is presented in figure 2 .

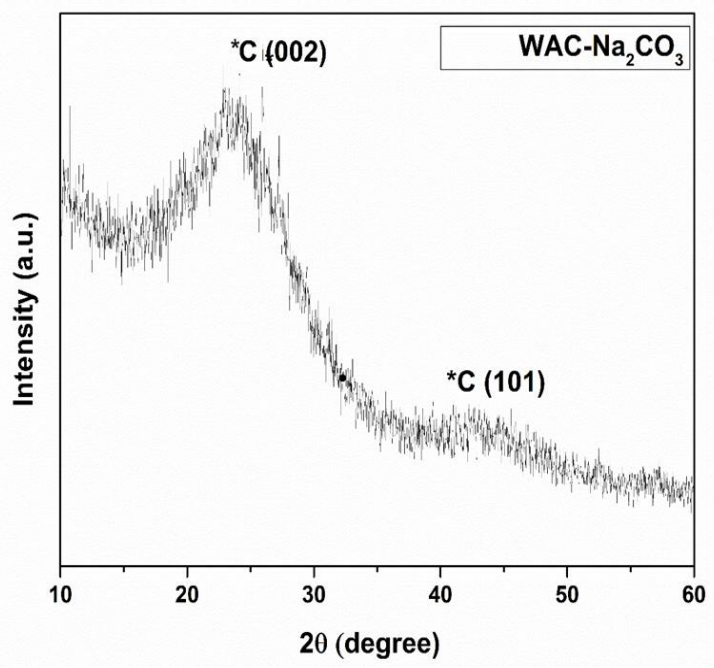

Fig. 2. XRD pattern of $\mathrm{WAC}-\mathrm{Na}_{2} \mathrm{CO}_{3}$

As can be seen in figure 2, the XRD pattern of the sample exhibit diffraction peaks at around $2 \theta=25$ degree. In the same way, WAC- $\mathrm{Na}_{2} \mathrm{CO}_{3}$ exhibited another weak peak at around $2 \theta=43$ degree. The diffraction peaks at around $2 \theta=25$ degree having 002 planes and $2 \theta=43$ degree having [101] plane assigned for hexagonal graphitic carbon (Liu et al., 2009). The XRD pattern indicates that the laboratory prepared activated carbons are amorphous, similar to commercial activated carbon and poorly graphitized.

\section{Fourier Transform Infrared Spectroscopy (FTIR)}

In figure 3 , the spectra clearly indicate the creation of surface functional groups on the surface of sample. It may be due to an effect of activating agent used during carbonization.

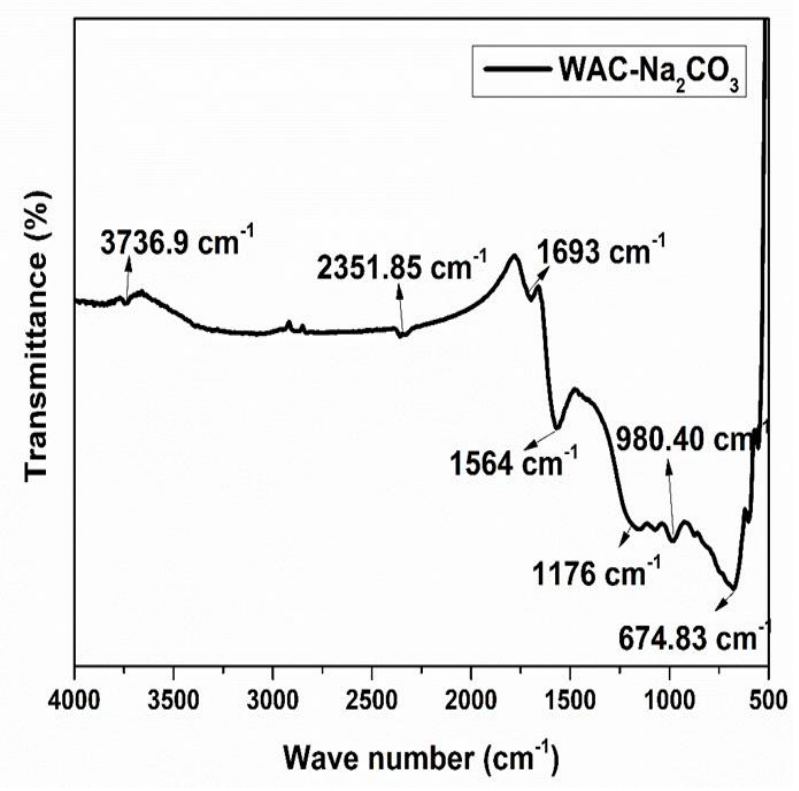

Fig. 3. FTIR Spectra of $\mathrm{WAC}-\mathrm{Na}_{2} \mathrm{CO}_{3}$

The small peak at around $2353 \mathrm{~cm}^{-1}$ in FTIR spectra is recognized for the presence of C-N group. The band at $1680 \mathrm{~cm}^{-1}$ was likely to be a combination of the carboxyl $\mathrm{C}=\mathrm{O}$ stretching of non aromatic carboxylic acid and lactone structure. Similarly, the next band is observed at the region around 1576 $\mathrm{cm}^{-1}$ which may be assigned to a combination of $\mathrm{C}=\mathrm{C}$ stretching vibration of the aromatic ring structures and conjugated systems such as diketone, ketoester and quinine $\left(1550-1680 \mathrm{~cm}^{-1}\right)$. The band at $1300-1000 \mathrm{~cm}^{-1}$ may be probably due to the C-O$\mathrm{C}$ lactone structure, the stretching $\mathrm{C}-\mathrm{O}$ vibrations of phenol structures and ethers, and the bending $\mathrm{O}-\mathrm{H}$ modes of phenol structures. Similarly, the band at $1700 \mathrm{~cm}^{-1}$ is attributed due to the presence of $\mathrm{C}=\mathrm{O}$ stretching (Joshi et al., 2014).

\section{BET Surface Area}

BET surface area WAC- $\mathrm{Na}_{2} \mathrm{CO}_{3}$ was found to be $10.45 \mathrm{~m}^{2} / \mathrm{g}$, which is considered to be small. It may be due to break down of walls of micro as well as mesopores and certainly due to the formation of macropores.

\section{Cyclic Voltammetry}

Figure 4 shows the cyclic voltamogram of WAC$\mathrm{Na}_{2} \mathrm{CO}_{3}$ at the scan rate of $100 \mathrm{mVs}^{-1}$ for 100 cycles measured in $0.5 \mathrm{M} \mathrm{H}_{2} \mathrm{SO}_{4}$ aqueous electrolyte solution within a potential range of -0.5 to 1 volt against saturated calomel as reference electrode. In figure 4 , one can see the current density of $1^{\text {st }}$ cycle was $0.21 \mathrm{~A} / \mathrm{g}$. But there was slight decrease in current density after 10 cycles. 


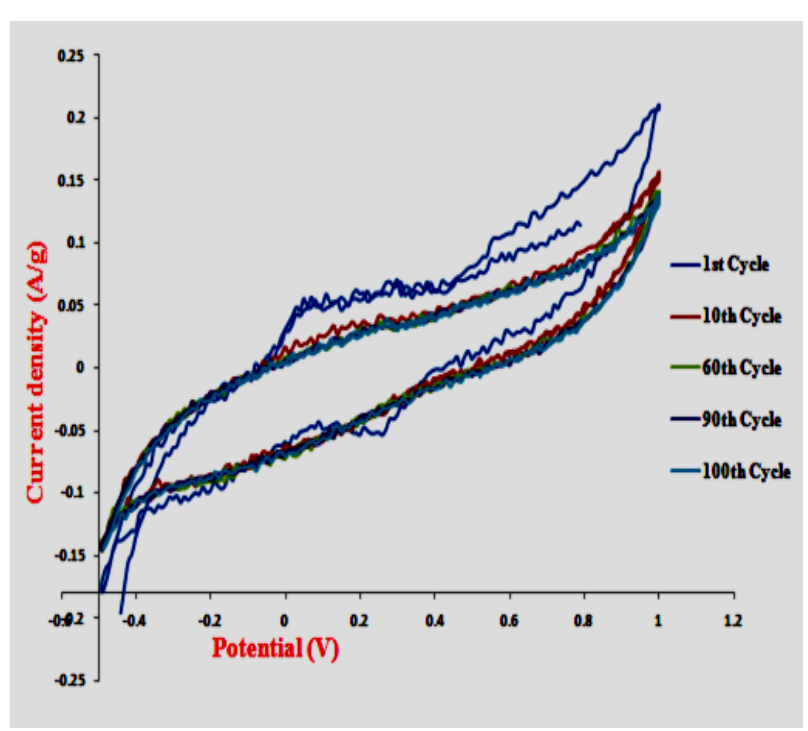

Fig. 4. Cyclic Voltamogram of $\mathrm{WAC}-\mathrm{Na}_{2} \mathrm{CO}_{3}$

However, the shape of $\mathrm{CV}$ was found to be rectangular indicating electrical double layer capacitance (EDLC) behavior. In the same way, CV shape is mirror symmetric even at high scan rate indicating the high reversibility of the sample. However, the specific capacitance was found to be $7.2 \mathrm{Fg}^{-1}$. This small capacitance value may be due to small surface area as indicated by BET surface area and development of macropores which was also perceived from SEM images. The low specific conductance value $3.2 \times 10^{-8} \mathrm{~S} / \mathrm{cm}$ also supports for the obtaining of less capacitance value. Low specific conductance means high resistance. It was probably due to presence of wax as a binder during electrode preparation.

\section{CONCLUSION}

It has been concluded that activated carbon can be prepared by using sawdust of Shorea robusta (Sal), by carbonization in a tube furnace at $400^{\circ} \mathrm{C}$, for 3 hours, in an inert atmosphere of nitrogen. According to proximate analysis, the moisture content, ash content and total carbon were found to be $8.56 \%, 1.07 \%$ and $48.0 \%$ respectively. This indicates that the sawdust precursor is suitable for preparing activated carbon. From the SEM image, it has been concluded that the porous surface formation was a consequence of chemical activation. The FTIR spectra confirmed that sample contained oxygenated functional groups such as diketone, lactone and ether. The XRD pattern at around $2 \theta=25$ degree having 002 planes and $2 \theta=$ 43 degree having [101] plane assigned for poorly graphitic carbon, however broad peak showed amorphous nature.

The electrodes prepared from activated carbon showed a small current response during cyclic voltammetry measurement. Similarly, the specific capacitance was found to be low. It might be due to high resistance because specific conductivity value was also found to be low. These values are quite reasonable as the specific surface area was found to be small. The abundance of macropores may be another reason for low capacitance. However, rectangular shape of $\mathrm{CV}$ curve showed electrical double layer capacitive behavior. Conversely, it needs further enhancement of surface area for significant improvement in capacitive behavior.

\section{ACKNOWLEDGEMENT}

DS is thankful to Institute of Science and Technology, Tribhuvan University to conduct $\mathrm{Ph}$. D. research in Central Department of Chemistry, Kirtipur. Global Research Laboratory, Sun Moon University is highly acknowledged for recording SEM, XRD and FTIR.

\section{REFERENCES}

ASTM (1999). Standard test method for determination of iodine number of activated carbon ASTM Annual Book., 4: D4607D4694.

ASTM (2009). Standard Terminology of Coal and Coke, D121-09a.

Becker, H. I. (1957). Low voltage electrolytic capacitor. United States Patent, 2800616.

Béguin, F. and Frackowiak, E. (2010). Carbons for Electrochemical Energy Storage and Conversion Systems. Boca Raton Taylor \& Francis, ISBN: 9781420053074.

Chowdhury, Z. Z.; Zain, S. M.; Khan, R. A; and Islam, S. (2012). Preparation and characterizations of activated carbon from kenaf fiber for equilibrium adsorption studies of copper from waste water. Journal of Applied Sciences Engineering and Technology, 29 (9): 1187-1195.

Endo, M., Takeda, T., Kim Y. J., Koshiba, K. and Ishii, K. (2001). High power electric double layer capacitor (EDLC's): from operating principle to pore size control in advanced activated carbons. Carbon Science, 1:117128. 
Frackowiak, E. (2007). Carbon materials for supercapacitor application. Physical Chemistry, 9: 1774-1785.

Frackowiak, E. and Béguin, F. (2001). Carbon materials for the electrochemical storage of energy in capacitors. Carbon, 39: 937-950.

Joshi, S.; Shrestha, L. K.; Kamachi, Y.; Yamuchi, Y.; Pradhananga, M. A.; Pokhrel, B. P. et al. (2014). Sodium hydroxide activated nanoporous carbons based on lapsi seed stone. Journal of Nanoscience and Nanotechnology, 14: 1-8.

Liu, C.; Li, F.; Ma, L. P. and Cheng, H. M. (2010). Advanced Materials for Energy Storage. International Science, 22: E28-E62.

Nahil, M. A. and Williams, P. T. (2012). Pore characteristics of activated carbons from the phosphoric acid chemical activation of cotton stalks. Biomass and Bioenergy, 37:142-149.
Pandolfo, A. G. and Hollenkamp, A. F. (2006). Carbon properties and their role in supercapacitors. Journal of Power Source, 157: 11-27.

Sharma, P. and Bhatti, T. S. (2010.) A review on electrochemical double-layer capacitors. Energy Conversion Management, 51: 29012912.

Simon, P. and Gogotsi, Y. (2008). Materials for electrochemical capacitors. Nature Materials, 7: 845-854.

Wang, G. P., Zhang, L. and Zhang, J. J. (2012). A review of electrode materials for electrochemical super capacitors. Chemical Society Review, 41: 797-828.

Zhang, L. L. and Zhao, X. S. (2009). Carbon-based materials as super capacitor electrodes. Chemical Society Review, 38: 2520-2531. 